\title{
Cognitive remediation improves cognition and good cognitive performance increases time to relapse - results of a 5 year catamnestic study in schizophrenia patients
}

Wolfgang Trapp ${ }^{1 *}$, Michael Landgrebe ${ }^{1}$, Katharina Hoesl ${ }^{1}$, Stefan Lautenbacher ${ }^{2}$, Bernd Gallhofer ${ }^{3}$, Wilfried Günther ${ }^{1}$ and Goeran Hajak ${ }^{1}$

\begin{abstract}
Background: Cognitive deficits are stable features of schizophrenia that are linked to functional outcome. Cognitive remediation approaches have been proven successful in ameliorating these deficits, although effect sizes vary considerably. Whether cognitive deficits are serious predictors of clinical outcome is less clear.

Methods: Sixty patients suffering from schizophrenia were included in our sample, thirty of them received computer-assisted cognitive training, and thirty received occupational therapy. For a subsample of 55 patients, who could be traced over a period of five years after the end of the cognitive remediation intervention, time until first relapse and time in psychosis were determined retrospectively from their medical records.

Results: Cognitive remediation significantly improved problem solving, memory and attention with high effect sizes. Employment status, a post test verbal memory performance measure and a measure of executive functioning outperformed all other measures in the prediction of time to relapse, while allocation to treatment group outperformed all other variables in the prediction of both cognitive measures.
\end{abstract}

Conclusions: Cognitive remediation of neurocognitive deficits thus makes sense in a twofold fashion: It enhances cognition directly and positively acts on clinical course indirectly via improved neurocognition.

Trial registration: German Clinical Trials Register: DRKS00004880

Keywords: Schizophrenia, Cognition, Cognitive remediation, Outcome, Prediction, Clinical course

\section{Background}

In the last decades there has been growing interest in the topic of cognitive functioning in schizophrenia, starting from initial hints that cognitive deficits might be significant predictors of social and vocational functioning after (successful) treatment of psychotic symptoms. A huge number of studies were conducted to answer several key questions:

\footnotetext{
* Correspondence: wolfgang.trapp@sozialstiftung-bamberg.de

'Department of Psychiatry, Sozialstiftung Bamberg, St-.Getreu-Straße 14-18, 96049 Bamberg, Germany

Full list of author information is available at the end of the article
}

Do schizophrenia patients suffer from stable cognitive deficits?

A substantial number of studies - as summarized in several meta-analyses [1-3] - report stable deficits in many cognitive domains, such as attention, verbal and visual (working-) memory and executive functions. High effect sizes of 1.0 and above indicate robust impairments. There is empirical evidence that cognitive impairment can be also found before first onset [4] and in persons at risk for schizophrenia (children, siblings, parents of schizophrenia patients) [5,6] while there is currently some debate about whether these cognitive deficits are specific enough to serve as diagnostic criteria for schizophrenia (see for example [7] vs. [8]).

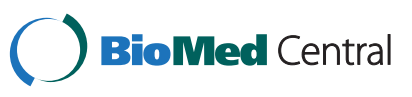

(c) 2013 Trapp et al.; licensee BioMed Central Ltd. This is an Open Access article distributed under the terms of the Creative Commons Attribution License (http://creativecommons.org/licenses/by/2.0), which permits unrestricted use, distribution, and reproduction in any medium, provided the original work is properly cited. 


\section{Are cognitive deficits important?}

Many studies have analyzed functional consequences of cognitive deficits and have found small to moderate correlations with functional outcome [9-11]: Cognitive performance seems to be linked to social skills, community functioning, social behavior, social problem solving [12] and even the probability of returning to work or school [13] regardless of potential moderator variables such as age, gender, inpatient status and illness chronicity. Even linkages to further clinical course of illness have been reported by some authors [14-18], although predictive power was limited and there are several studies that could not find any significant relations with neurocognition [19-21].

\section{Is it possible to remediate neurocognitive deficits?}

Three recent meta-analyses considering a huge number of patients have focused on the effects of cognitive remediation in schizophrenia [22-24] reporting effect sizes for overall cognition of 0.38 to 0.45 with effect sizes of about the same for follow-up assessments. Cognitive remediation seems to be more effective when combined with psychiatric rehabilitation interventions and may boost the effects of other remediation programs. The authors agree in their estimation that the effect sizes are rather unaffected by age of the participants, use of computers, frequency and duration of training as well as type of control condition (active or treatment as usual). However, when cognitive remediation therapy is combined with adjunctive psychiatric rehabilitation and when social functioning is considered, strategy based training approaches appear to be superior to pure 'drill and practice' approaches [25].

In a former trial [26] we assessed the effects of computer-aided cognitive training using a very game-like and motivating software [27] in forty outpatients suffering from schizophrenia. Twenty of the participants received cognitive training; twenty received occupational therapy twice a week for ten weeks. Enhancing effects on executive functioning level and verbal memory as well as effects on positive and negative symptom levels could be found.

Studies linking cognitive remediation and long-term clinical course of schizophrenia are rare.

The present study describes effects of a cognitive remediation intervention using the same cognitive training software on cognitive performance of 60 schizophrenia inpatients and implications for their further clinical course over a period of 5 years. We hypothesized that our intervention has a strong effect on cognitive performance and that good cognitive performance improves participants' clinical outcome.

\section{Methods}

\section{Participants}

Sixty inpatients of the psychiatric hospital in Bamberg, Germany were included. All of them fulfilled the Inter- national Classification of Diseases-10 (ICD-10), as well as the Diagnostic and Statistical Manual of Mental Disorders-IV (DSM-IV) criteria for schizophrenia and were diagnosed based on the Structured Clinical Interview for the DSM-IV (SCID) [28] performed by physicians blind to treatment allocation. After a complete description of the study, written informed consent was obtained from all subjects. The study adhered to the principles of Good Clinical Practice of the International Conference on Harmonization and the Declaration of Helsinki and was approved by the local ethics board (University of Bamberg).

Thirty patients were included in the experimental group (EG) and thirty patients matched by gender, age and educational level formed the control group (CG). Clinical and demographic characteristics of all participants are described in Table 1.

The experimental group received four 60-minute training sessions per week for three weeks during their stay at the psychiatric ward (twelve sessions in total) using the "game-like" cognitive training software $\mathrm{X}-\mathrm{Cog}^{\circ}$, that was explicitly designed to motivate patients as much as possible while "playing" the tasks (for more details see [26]). The version administered to the patients consisted of sixteen visuomotor, memory, problem-solving and attention tasks. Participants had to control characters that face several adventurous challenges, such as rescuing a princess which has been captured inside of a maze, protecting salads from hungry snails etc. Each task can be administered in five different levels of difficulty from 'beginner' to 'superprofessional'. Every time a specified level for each task is mastered successfully completed, this is indicated by the software, and the participants

Table 1 Demographic and clinical characteristics

\begin{tabular}{|c|c|c|c|c|}
\hline \multirow[t]{2}{*}{ Characteristic } & \multicolumn{2}{|c|}{$\begin{array}{c}\text { Experimental } \\
\text { group }(n=30)\end{array}$} & \multicolumn{2}{|c|}{$\begin{array}{c}\text { Control group } \\
(n=30)\end{array}$} \\
\hline & $\mathbf{N}$ & $\%$ & $\mathrm{~N}$ & $\%$ \\
\hline \multicolumn{5}{|l|}{ Gender } \\
\hline Male & 15 & 50.0 & 15 & 50.0 \\
\hline Female & 15 & 50.0 & 15 & 50.0 \\
\hline \multicolumn{5}{|l|}{ Medication } \\
\hline Atypical antipsychotic & 10 & 33.3 & 11 & 36.7 \\
\hline Typical antipsychotic & 1 & 3.3 & 4 & 13.3 \\
\hline Both & 19 & 63.3 & 15 & 50.0 \\
\hline Partnership & 12 & 40 & 8 & 26.7 \\
\hline Employment status (working) & 12 & 40 & 13 & 43.3 \\
\hline \multirow[t]{2}{*}{ Housing in own apartment / house } & 19 & 63.3 & 20 & 66.7 \\
\hline & Mean & SD & Mean & SD \\
\hline Age & 36.43 & 12.99 & 36.87 & 14.65 \\
\hline Years of education & 10.83 & 3.25 & 10.47 & 2.45 \\
\hline Duration of illness & 7.93 & 8.28 & 8.97 & 9.65 \\
\hline
\end{tabular}


then move up to the next level of difficulty. Figure 1 presents screen shots and short descriptions for some selected tasks; a free trial version of the software can be downloaded at www.x-cog.de/xcogen.html.

In small groups of three to four patients, 16 tasks that target attention, verbal and visuospatial memory as well as problem solving skills were administered by either one experienced psychologist or occupational therapist who selected the appropriate (and increasing) degree of difficulty based on the participants' achievement level. All participants completed all 12 training sessions.

Instead of cognitive remediation sessions, CG patients received twelve sessions of occupational therapy (painting and handicraft). Participants were told that they will receive cognitive training or occupational therapy to improve their mental performance.

Additionally to cognitive remediation or occupational therapy, all patients of both groups received antipsychotic drug therapy and periodic visits by a clinical psychiatrist, most of the patients (70 to 80 Percent in both groups) furthermore received sports therapy and music therapy once a week. Furthermore a minority of patients (30 to 40 percent in both groups) attended relaxation therapy groups (twice a week) and received CBT sessions guided by a psychologist (once a week).
After their inpatient stay, those patients that could be traced had regular brief (ten to twenty minutes) appointments with their attending psychiatrist about once per month. Both groups did not differ with respect to the frequency of these other therapeutic interventions. Participants were recruited and assigned to either experimental or control group alternatively in two blocks of 15 patients each in order to blind EG participants to the treatment of the CG and vice versa. Symptom levels were obtained before and after treatment for all patients using German versions of the Scale for the Assessment of Positive Symptoms (SAPS) [29], the Scale for the Assessment of Negative Symptoms (SANS) [30] both rated by a senior psychiatrist who was blind to treatment allocation and the Paranoid-Depression Scale (PD-S) selfrating-scale [31]. Inter-rater reliability was not assessed.

Cognitive functioning was assessed using the Wisconsin Card Sorting Test (WCST) [32], the German version of the Wechsler Memory Scale (WMS-R) [33], the Trail Making Test (TMT) Part A und B [34] and two versions of the Continuous Performance Test (CPT) for the assessment of sustained attention: The degraded CPT [35] and the 3-7 CPT [36]: In the degraded version, participants had to respond to a target blurred digit ' 3 ' in a pseudorandomized sequence of blurred digits, while in the

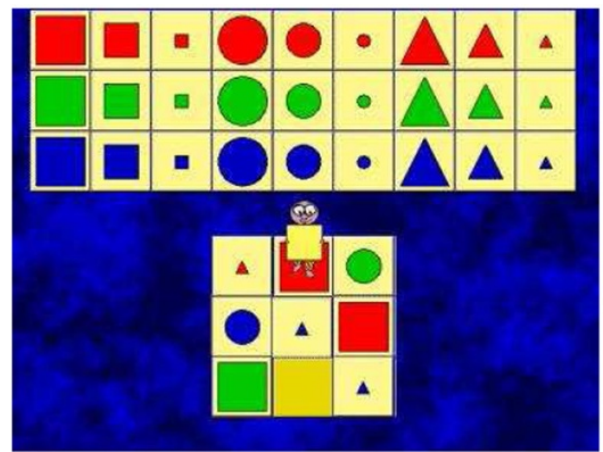

Magic carpet: 8 tiles are positioned in a $3 * 3$ square matrix. The missing tile has to be completed following the implicit logical rules for color, shape and size.

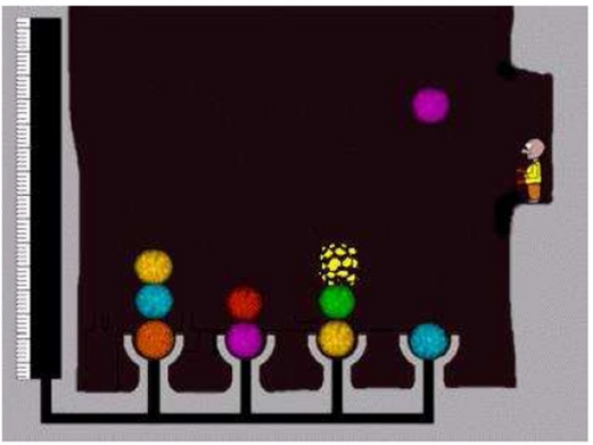

Fruit press: To create pink fruit juice, falling comets have to be sorted in dishes. Special comets can't be sorted and have to be destroyed while falling

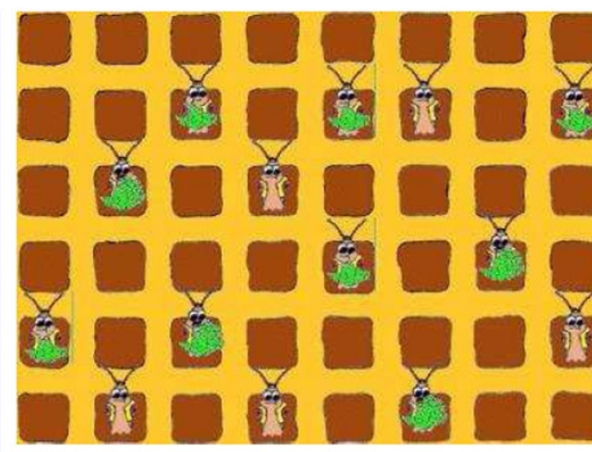

Salad clash: Hungry snails dig themselves into salad beds. The players have to remember where the snails are hidden, when they seed new salad plants.

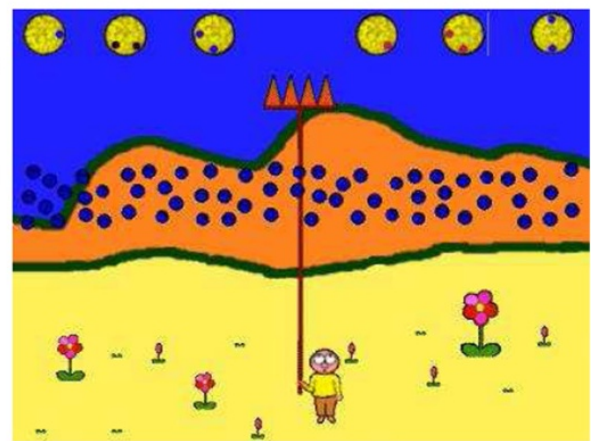

Rainmaker: To pour a flower field a comet-fork has to stabbed into passing comets. But only some distinct comets contain water

Figure 1 Screen shots and descriptions of some selected tasks in X-Cog. 
3-7 version subjects had to respond to each ' 7 ' that follows a ' 3 '.

Our sample size provides $85 \%$ power to detect an improvement of 30 percent in the WCST 'total errors' measure for the experimental group compared to the control group for a two study groups design using a continuous primary endpoint [37] when the estimated standard deviation was taken from the former cognitive remediation study described above.

Five years after end of treatment, time until rehospitalisation (if any) for those patients, who could be traced (28 patients from the EG, 27 patients from the control group) was assessed retrospectively from the medical records of attending physicians / psychiatric hospitals. Each inpatient stay of at least three consecutive days during the follow-up period was considered a rehospitalisation. In fact, the minimum duration of stay found in our sample was 5 days, so every inpatient stay for all of our participants was included in the analyses. Additionally total time in psychosis was obtained as a measure of treatment intensity by adding the days of all inpatient stays during the follow up period.

\section{Data analysis}

In a first step, $\mathrm{t}$-tests for independent samples and chi-square tests were performed to evaluate differences in CG and EG at pre-test time.

Then, to avoid multiple testing, multivariate analyses of variance were computed using treatment group (EG vs. CG) as group factor, "time" (pretest at day 1 vs. posttest at day 14) as repeated measures factor and the following (groups of) dependent variables:

- Attention (degraded and 3-7 CPT measures)

- problem solving (WCST measures and TMT B minus TMT A processing time)

- memory (WMS scores),

- processing speed (TMT A and B processing time),

- positive symptoms (SAPS subscales),

- negative symptoms (SANS subscales) and

- self-rating scores of depressive and paranoid symptoms (PD-S subscales).

For those multivariate analyses that showed significant $(\mathrm{p}<0.05)$ interaction effects 'group $\mathrm{x}$ time' and thus indicated differential effects of cognitive training, univariate ANOVAS for each dependent variable were performed. Parts of these results for a subset of the neurocognitive measures collected have already been published elsewhere [38].

A Cox regression survival analysis was performed to figure out measures that may predict time until patients' next relapse. Information about the patient's clinical and demographical data (partnership, years of education, post-treatment employment status, time since onset of illness and habitation status, medication, gender, age) as well as cognitive achievement level and symptom level at pre and posttest were introduced as independent variables in a stepwise procedure. Based on their standardized regression weights Odds-Ratio values were computed for those variables included in the equation.

To figure out possible predictors of patients' time in psychosis a linear stepwise regression analysis was performed using time in psychosis as dependent variable and the same set of variables as for the Cox regression described above as predictors.

Since posttest WMS-R verbal memory performance and WCST perseveration errors were the only cognitive variables that significantly predicted time until relapse and time in psychosis, two stepwise linear regression analyses were performed using either verbal memory scores or WCST perseveration errors at posttest as dependent variable in order to search for possible predictors of both cognitive measures. All baseline measures, including "allocation to treatment group" (EG vs. CG) were included as independent variables.

\section{Results}

Clinical and demographic characteristics as well as neurocognitive measures of all participants are described in Tables 1,2 and 3 - the groups did not differ in any of the measures shown ( $\mathrm{t}$-values between .01 and 1.39, n.s.; $X^{2}$ for medication, housing, partnership and working: 2.32, .73, 1.20, .69, n.s.) except for the total number of WCST errors where EG patients showed a trend towards higher scores $(\mathrm{t}=1.99, \mathrm{p}=.053)$.

Results of multivariate and univariate ANOVAS for neurocognitive measures are shown in Table 2. As can be seen, significant multivariate interaction effects could be found for attention, memory and problem solving measures while no differential changes for EG and CG from pre to posttest could be found for processing speed.

Univariate analyses revealed significant interaction effects for degraded CPT commission, 3-7 CPT omissions as well as all problem solving and memory measures. Inspection of mean values shows an improvement of performance only for EG patients while achievement measures appear unchanged for CG patients.

The corresponding results for symptom measures are displayed in Table 3. Only SAPS and PD-S scales show significant multivariate interaction effects. Univariate analyses point to stronger decreases in SAPS 'delusions' as well as in self-rated 'paranoid' and 'depressive' symptoms for EG patients.

Mean time until first relapse for those participants experiencing any relapse was 526.6 days $(\mathrm{SD}=425.8$, $\mathrm{n}=20)$ for the experimental and 390.1 days $(S D=433.0$, 
Table 2 Mean values and results of repeated measures analyses of variance: neurocognitive measures

\begin{tabular}{|c|c|c|c|c|c|c|c|c|c|c|}
\hline \multirow[b]{3}{*}{ Measure } & \multicolumn{2}{|c|}{$E G(n=30)$} & \multicolumn{2}{|c|}{ CG $(n=30)$} & \multirow{2}{*}{\multicolumn{2}{|c|}{$\begin{array}{l}\text { Main effect } \\
\text { "group" }\end{array}$}} & \multirow{2}{*}{\multicolumn{2}{|c|}{$\begin{array}{l}\text { Main effect } \\
\text { "time" }\end{array}$}} & \multirow{2}{*}{\multicolumn{2}{|c|}{$\begin{array}{c}\text { Interaction } \\
\text { "time x group" }\end{array}$}} \\
\hline & \multirow{2}{*}{$\begin{array}{c}\text { Pretest } \\
\text { mean (SD) }\end{array}$} & \multirow{2}{*}{$\begin{array}{c}\text { Posttest } \\
\text { mean (SD) }\end{array}$} & \multirow{2}{*}{$\begin{array}{c}\text { Pretest } \\
\text { mean (SD) }\end{array}$} & \multirow{2}{*}{$\begin{array}{c}\text { Posttest } \\
\text { mean (SD) }\end{array}$} & & & & & & \\
\hline & & & & & $\begin{array}{c}F_{(4 / 55)} \\
m v . \\
F_{(1 / 58)} \\
\text { uv. }\end{array}$ & $p$ & $\begin{array}{c}F_{(2 / 57)} \\
\text { mv. } \\
F_{(1 / 58)} \\
\text { uv. }\end{array}$ & $p$ & $\begin{array}{c}F_{(2 / 57)} \\
\text { mv. } \\
F_{(1 / 58)} \\
\text { uv. }\end{array}$ & $p$ \\
\hline Attention (multivariate) & & & & & .578 & .680 & 5.266 & .001 & 4.606 & .003 \\
\hline Degraded CPT omissions & $15.48(14.45)$ & $10.54(10.99)$ & $15.44(14.60)$ & $13.92(12.77)$ & .029 & .866 & 5.830 & .019 & 1.639 & .206 \\
\hline Degraded CPT comissions & $2.59(2.28)$ & $1.03(1.49)$ & $1.85(1.95)$ & $1.98(3.45)$ & .038 & .847 & 6.086 & .017 & 8.561 & .005 \\
\hline 3-7 CPT omissions & $26.05(16.24)$ & $18.70(13.34)$ & $23.80(14.23)$ & $24.07(16.85)$ & .205 & .652 & 3.537 & .065 & 4.104 & .047 \\
\hline 3-7CPT comissions & $1.68(1.71)$ & $0.89(0.92)$ & $1.87(2.14)$ & $1.81(2.35)$ & 1.562 & .216 & 4.971 & .030 & 3.725 & .059 \\
\hline Memory (multivariate) & & & & & 1.557 & .220 & 63.811 & $<.0005$ & 51.214 & $<.0005$ \\
\hline $\begin{array}{l}\text { WMS composite score "verbal } \\
\text { memory" }\end{array}$ & $83.03(18.16)$ & $\begin{array}{l}103.27 \\
(15.74)\end{array}$ & $84.23(24.58)$ & $87.10(21.63)$ & 2.267 & .138 & 47.757 & $<.0005$ & 26.993 & $<.0005$ \\
\hline $\begin{array}{l}\text { WMS composite score "visual } \\
\text { memory" }\end{array}$ & $77.23(12.62)$ & $\begin{array}{l}101.03 \\
(12.03)\end{array}$ & $83.57(16.44)$ & $83.27(18.73)$ & 2.597 & .112 & 48.653 & $<.0005$ & 51.170 & $<.0005$ \\
\hline Problem solving (multivariate) & & & & & 1.694 & .179 & 7.895 & $<.0005$ & 20.416 & $<.0005$ \\
\hline WCST \% total errors & $28.69(3.84)$ & $19.94(3.45)$ & $25.23(8.71)$ & $27.78(7.90)$ & 2.188 & .145 & 17.427 & $<.0005$ & 57.793 & $<.0005$ \\
\hline WCST $\%$ failure to maintain set & $6.79(3.80)$ & $3.28(2.12)$ & $5.66(4.29)$ & $6.47(4.82)$ & 1.263 & .266 & 10.590 & .002 & 26.918 & $<.0005$ \\
\hline WCST $\%$ perseveration errors & $9.11(4.45)$ & $2.87(2.22)$ & $7.53(5.42)$ & $8.74(6.45)$ & 3.920 & .052 & 15.192 & $<.0005$ & 33.180 & $<.0005$ \\
\hline TMT B-A & $80,53(48,93)$ & $53.13(23.65)$ & $88.13(56.80)$ & $77.47(49.42)$ & 2.147 & .148 & 14.513 & $<.0005$ & 2.804 & .046 \\
\hline Speed of processing & & & & & 1.120 & .333 & 11.489 & $<.0005$ & 2.026 & .141 \\
\hline TMT A performance time & $49.43(20.21)$ & $40.77(16.49)$ & $49.90(20.27)$ & $46.20(15.19)$ & & & & & & \\
\hline TMT B performance time & $\begin{array}{l}129.97 \\
(63.70)\end{array}$ & $93.90(37.04$ & $\begin{array}{l}138.03 \\
(72.96)\end{array}$ & $\begin{array}{l}123.67 \\
(56.66)\end{array}$ & & & & & & \\
\hline
\end{tabular}

Table 3 Mean values and results of repeated measures analyses of variance: symptom measures

\begin{tabular}{|c|c|c|c|c|c|c|c|c|c|c|}
\hline \multirow[b]{3}{*}{ Measure } & \multicolumn{2}{|c|}{$E G(n=30)$} & \multicolumn{2}{|c|}{ CG $(n=30)$} & \multirow{2}{*}{\multicolumn{2}{|c|}{$\begin{array}{c}\text { Main effect } \\
\text { "group" }\end{array}$}} & \multirow{2}{*}{\multicolumn{2}{|c|}{$\begin{array}{c}\text { Main effect } \\
\text { "time" }\end{array}$}} & \multirow{2}{*}{\multicolumn{2}{|c|}{$\begin{array}{c}\text { Interaction } \\
\text { "time x group" }\end{array}$}} \\
\hline & \multirow{2}{*}{$\begin{array}{c}\text { Pretest } \\
\text { mean (SD) }\end{array}$} & \multirow{2}{*}{$\begin{array}{c}\text { Posttest } \\
\text { mean (SD) }\end{array}$} & \multirow{2}{*}{$\begin{array}{c}\text { Pretest } \\
\text { mean (SD) }\end{array}$} & \multirow{2}{*}{$\begin{array}{c}\text { Posttest } \\
\text { mean (SD) }\end{array}$} & & & & & & \\
\hline & & & & & $\begin{array}{l}F_{(4 / 55) ~ m v .} \\
F_{(1 / 58) \text { uv. }}\end{array}$ & $\mathrm{p}$ & $\begin{array}{l}F_{(2 / 57) ~ m v .} \\
F_{(1 / 58) \text { uv. }}\end{array}$ & p & 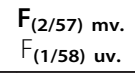 & p \\
\hline SAPS scales (multivariate) & & & & & 1.372 & .256 & 36.896 & $<.0005$ & 4.475 & .003 \\
\hline hallucinations & $1.48(.82)$ & $.22(.50)$ & $1.72(1.00)$ & $.76(.89)$ & 4.210 & .045 & 126.744 & $<.0005$ & 2.433 & .124 \\
\hline delusions & $1.85(.82)$ & $.44(.41)$ & $1.79(.93)$ & $1.15(.76)$ & 3.573 & .064 & 116.570 & $<.0005$ & 16.464 & $<.0005$ \\
\hline Bizarre behavior & $.85(.73)$ & $.29(.39)$ & $.61(.70)$ & $.49(.49)$ & .243 & .624 & 17.415 & $<.0005$ & 3.635 & .062 \\
\hline positive formal thought disorder & $.98(1.08)$ & $.48(.68)$ & $.91(.82)$ & $.52(.49)$ & .002 & .963 & 18.452 & $<.0005$ & .282 & .598 \\
\hline SANS scales (multivariate) & & & & & 1.611 & .173 & 8.128 & $<.0005$ & .631 & .677 \\
\hline Affective flattening or blunting & $1.43(1.35)$ & $.87(.83)$ & $1.93(1.44)$ & $1.25(1.09)$ & & & & & & \\
\hline alogia & $1.45(.85)$ & $.82(.91)$ & $1.74(1.21)$ & $1.38(1.19)$ & & & & & & \\
\hline Avolition / apathy & $1.18(1.37)$ & $.76(1.30)$ & $1.30(1.47)$ & $1.01(.98)$ & & & & & & \\
\hline Anhedonia / asociality & $1.49(1.26)$ & $.58(.96)$ & $1.88(1.24)$ & $1.26(1.09)$ & & & & & & \\
\hline attention & $1.13(1.26)$ & $.53(1.21)$ & $1.45(1.27)$ & $.75(.85)$ & & & & & & \\
\hline PD-S scales (multivariate) & & & & & 2.293 & .110 & 12.812 & $<.0005$ & 3.405 & .040 \\
\hline Paranoid thinking & $94.06(8.90)$ & $78.56(22.02)$ & $95.53(7.12)$ & $89.65(15.05)$ & 4.665 & .035 & 20.519 & $<.0005$ & 4.160 & .046 \\
\hline Depression & $85.83(16.97)$ & $68.93(24.53)$ & $83.81(28.92)$ & $79.64(26.19)$ & .587 & .447 & 13.749 & $<.0005$ & 5.017 & .029 \\
\hline
\end{tabular}


$\mathrm{n}=19$ ) for the control group. This difference does not reach statistical significance $(\mathrm{t}(37)=.99$, n.s. $)$.

The stepwise procedure in the Cox Regression analysis used to predict time to relapse stopped when two variables - employment status (currently in education or working paid or unpaid in a part- or full-time job vs. unemployed; Wald statistic $=6.54, \mathrm{p}=.011$, Odds-Ratio $=$ $1 / \exp (\mathrm{B})=2.54$ ) and verbal memory score at posttest (Wald statistic $=4.97, \mathrm{p}=.026$, Odds-Ratio $=1 / \exp (\mathrm{B})=$ 2.15 ) - were included in the equation. Figure 2 shows separate Kaplan Meier survival plots for both variables.

Only three predictors: verbal (beta $=.609, \mathrm{p}<.0005$ ) and visual memory (beta $=.236, \mathrm{p}=.007$ ) at baseline as well as "treatment" (beta $=.466, \mathrm{p}<.0005$ ) remained in the stepwise linear regression procedure's equation $\left(\mathrm{R}^{2}=.739\right)$ using post test verbal memory performance as dependent variable.

Average values for time in psychosis for those participants experiencing any relapse was shorter for the cognitive remediation group (mean $=75.0, \quad \mathrm{SD}=51.0$ ) than for the control group (mean $=140.4, S D=123.6$, $\mathrm{t}(37)=2.14, \mathrm{p}=.043$, Cohen's $\mathrm{d}=.58$ ). When time in psychosis and number of rehospitalisations is analyzed for the entire sample (with time in psychosis scored 0 for those patients without relapse) differences between both groups do not reach a two-sided $\alpha<.05$ level (mean values: $53.6(55.0)$ vs. $100.9(120.5), \mathrm{t}(53)=1.86, \mathrm{p}=.071$, Cohen's d $=.43)$.

In contrast to the results of the Cox regression for time until relapse, the stepwise linear regression procedure to predict time in psychosis resulted in an equation containing only one WCST variable for the entire sample (post-intervention perseveration errors, beta $=.292$, $\left.\mathrm{p}=.031, \mathrm{R}^{2}=.085\right)$. Two predictors: WCST total errors (beta $=.427, \mathrm{p}<.0005$ ) at baseline and "treatment" (beta $=.625, \mathrm{p}<.0005)$ remained in the stepwise linear regression procedure's equation $\left(\mathrm{R}^{2}=.409\right)$ using postintervention WCST perseveration errors as dependent variable.

Figure 3 summarizes all parameters that directly or indirectly predict time until relapse and time in psychosis in our sample.

\section{Discussion}

This study highlights positive effects of computer-aided cognitive training. We found independent general effects on participants' memory, attention and executive performance. When time to relapse and time in psychosis five years after the cognitive remediation intervention was analyzed in further detail, verbal memory and problem solving performance at posttest as well as employment status turned out to be the most economic predictors in a stepwise regression procedure. Surely, it is easier to influence cognitive performance during a few weeks inpatient stay and in our sample - even when all other potential influential factors assessed were taken into account - post-intervention cognitive achievement level seems to be solely influenced by performance level before training and training itself.

\section{Cognitive remediation effect sizes}

In our sample effects of CRT on nearly all cognitive domains assessed with effect sizes ranging from medium to high levels (Cohen's d values range from 0.35 for attention measures to 1.29 for WCST errors, see Table 4) could be found.

The finding that relatively small effect sizes for attention were obtained corresponds with the results of two recent meta analyses investigating the effects of CRT $[22,24]$ : The authors report similar Cohen's d values of
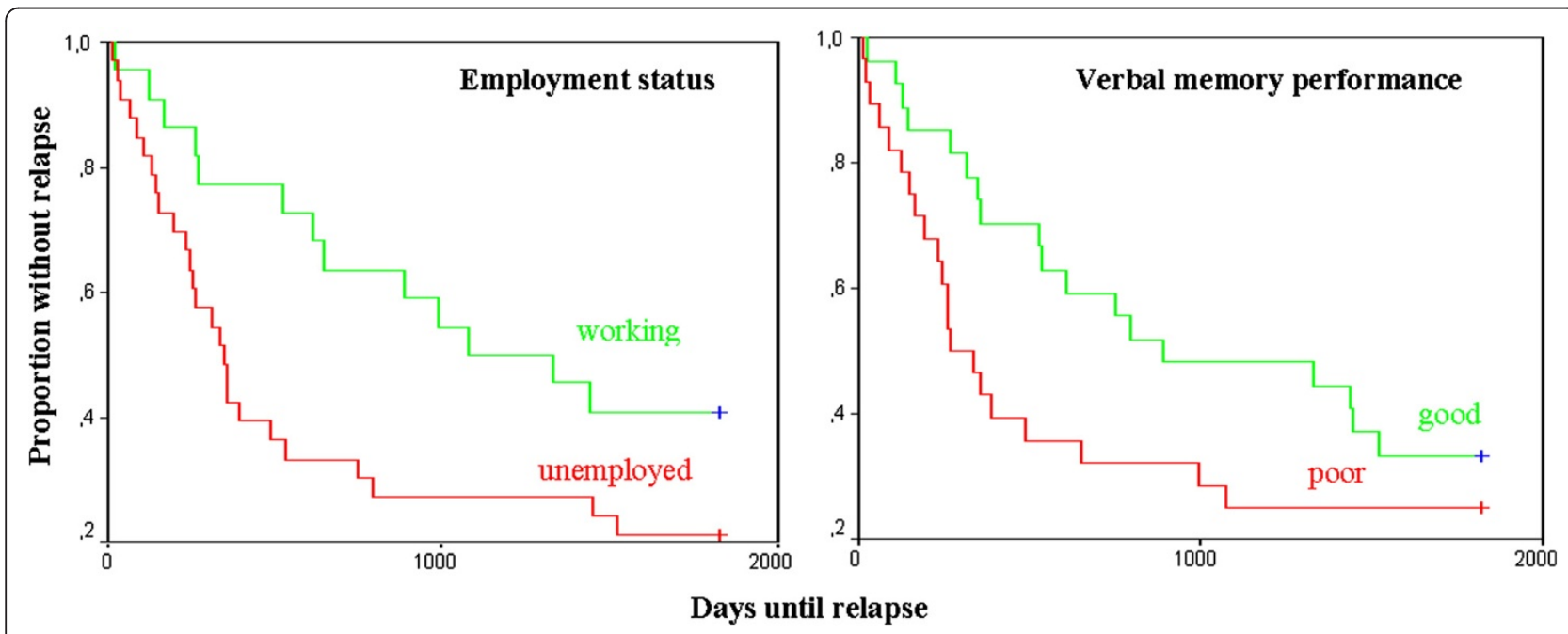

Days until relapse

Figure $\mathbf{2}$ Kaplan Meier survival plots for employment status and verbal memory performance at posttest. 


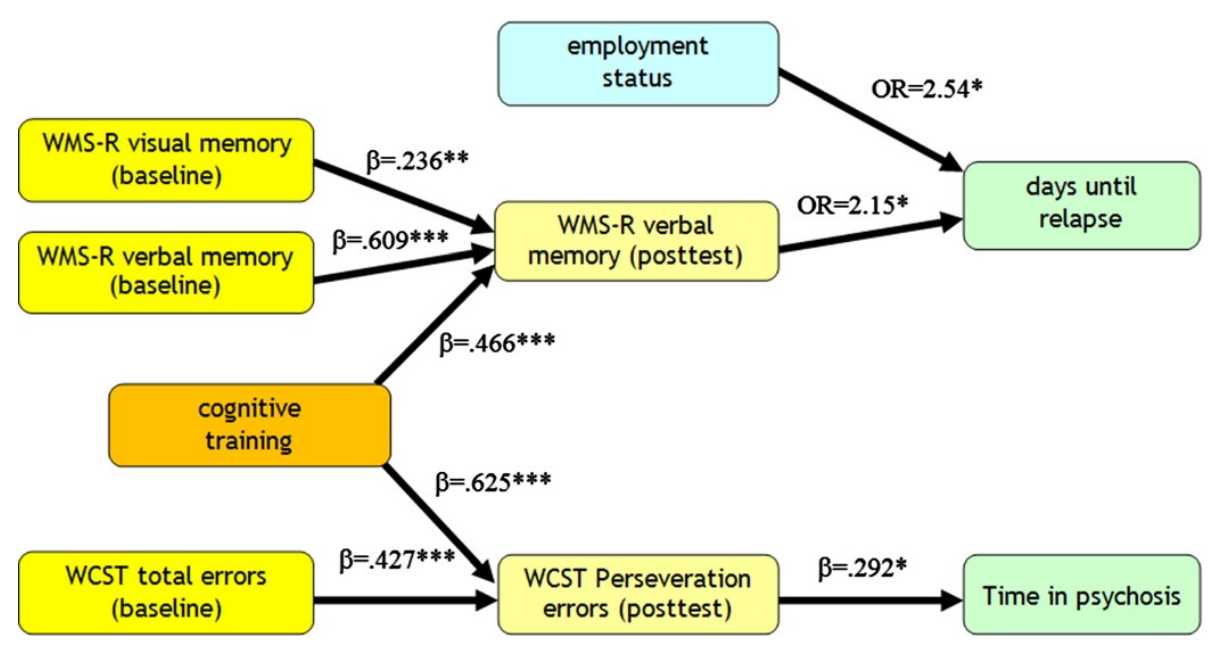

Figure 3 Measures predicting days until relapse and time in psychosis.

.28 and .25 for attention as well as lower values of .51 and .57 for problem solving, .37 and .41 for verbal and -.08 and .15 for visual memory compared to our findings. Visuospatial memory was not assessed in our outpatient study for it was not subject to training in contrast to the present contribution. And surprisingly the effect size is very high compared to an overall nonsignificant effect in the collected data of the recent reviews. Unfortunately the authors did not report which cognitive domains were addressed by cognitive remediation, so their findings may be partly due to the fact that nonverbal memory was not subject to cognitive training in many cases.

It is of course difficult to judge why the effect sizes for problem-solving and memory measures are higher in our two samples. One could argue, that the positive effects are just an incidental finding, although they were found in two independent samples comprising 100 patients in total.

Table 4 Effect sizes of significantly improved neurocognitive measures

\begin{tabular}{lc}
\hline Measure & Cohen's d \\
\hline Attention & .36 \\
Degraded CPT comissions & .35 \\
3-7 CPT omissions & \\
Memory & .85 \\
WMS composite score "verbal memory" & 1.13 \\
WMS composite score "visual memory" & \\
Problem solving & 1.29 \\
WCST \% total errors & .86 \\
WCST \% failure to maintain set & 1.22 \\
WCST \% perseveration errors & .63 \\
TMT B-A
\end{tabular}

One other obvious explanation could be that quality of both studies with respect to allocation to treatment is low (no randomization). But, as could be found recently, independent randomization seems to have no effect on the extent of the effects of cognitive remediation therapy [22].

\section{Neurocognition and clinical course}

As already stated in the 'introduction' section, cognitive impairment appears to be a stable feature in schizophrenic patients: It seems to be hardly affected by pharmacological antipsychotic treatment, tends to be stable over time and is present before and at onset of psychosis. Furthermore, there is broad empirical data, that cognitive deficits are linked to functional outcome, and that particular cognitive impairments may even serve as predictors of specific domains of functional outcome [12,39-41]. It is still unclear whether cognitive functioning is related to clinical outcome. By now, only very few studies examined associations of neurocognitive performance to measures like 'time in psychosis' or 'time to first relapse'. Unfortunately, those that discovered significant relationships considered shorter follow-up intervals and, maybe because of this, utilized weaker measures like 'clinical deterioration' as criterion for clinical outcome. The probability to get significant correlations of cognitive measures with clinical outcome may of course be higher when they are based on a shorter follow-up period.

Our finding that verbal memory performance and a measure of executive functioning predict time to first relapse and time in psychosis partly matches with results of former studies linking neurocognitive measures to clinical outcome.

Like in our sample, of those studies that revealed significant relationships between cognitive measures and clinical course two $[15,18]$ found significant relationships 
with verbal memory (although it has to be admitted that in [15] only self rating of memory performance was assessed). Two other studies did not assess verbal memory $([14,16]$, in $[14]$ verbal learning instead of delayed verbal memory was assessed) and in the remaining contribution [17] TMT-B score, a measure also focusing on cognitive flexibility similar to WCST perseveration errors score outperformed all other measures.

When transition to psychosis is used as a criterion for high-risk samples, verbal memory also repeatedly has been found to be the best predictor [42-44].

There are various possibilities, how cognitive impairment may influence further clinical course: On the one hand, as cognitive impairment is linked to poor functional outcome, insufficient functioning resources may in turn lead to higher stress levels resulting from insufficient coping with life-events and daily hassles. Psychosocial stress is considered a major risk factor for relapse of psychotic symptoms [45-47]. On the other hand good cognitive achievement levels may support treatment compliance and especially may prevent patients from forgetting to take their antipsychotic medication, or from missing appointments with their psychiatrists / consultants [48-50].

Cognitive training itself did not predict time to relapse and only a weak linkage to time in psychosis was found for the entire sample reaching statistical significance only on a one-sided $\alpha<.05$ level. This is not too surprising because cognitive achievement level of course is not only dependent from cognitive remediation interventions but from other factors like baseline achievement level also. However, in our sample cognitive remediation significantly affected cognitive achievement level even when baseline performance was controlled and therefore may have acted indirectly on further course of illness.

\section{Limitations and implications for future research}

Despite of encouraging results, our sample size of sixty patients is rather small compared to those of other studies examining the effects of CRT, which leads to weaker statistical power and makes it harder to generalize our findings.

Our finding that employment status was only linked to time until rehospitalisation might be due to the fact that only post-intervention employment status was assessed. It is likely that changes in employment level may have occurred and that these changes might have interacted with clinical outcome. Unfortunately we did not collect any data to verify this hypothesis.

Since relapse was determined retrospectively, milder forms of relapse prior to rehospitalisation remained undetected and thus were not included in the analyses.

Unfortunately, our participants were not allocated to treatment in a randomized fashion. This clearly reduces methodological quality and therefore at least the results of the cognitive training intervention should be regarded as preliminary, although, as stated above in this section, current empirical evidence seems to indicate that nonrandomized allocation does not influence effect sizes of cognitive training interventions.

\section{Conclusion}

This study provides preliminary evidence that cognitive training may be able to indirectly influence the long-term course of illness in schizophrenic patients: Two cognitive measures and a vocational variable outperformed all other variables as predictors. While it may be difficult to change patients' employment status during an inpatient stay in a psychiatric hospital, cognitive training could be a powerful instrument to boost cognition and by this means indirectly improve further course of illness.

This is of particular importance considering the chronic and disabling nature of this severe disease starting in early life.

\section{Competing interests}

The authors declare that they have no competing interests.

\section{Authors' contributions}

WT performed all statistical analyses and drafted the manuscript. BG, WG, WT and GH FG conceived of the study, and participated in its design and coordination. $\mathrm{ML}$ and $\mathrm{KH}$ helped to draft the manuscript. All authors read and approved the final manuscript.

\section{Acknowledgements}

We wish to thank Mrs. Sigrid Glaessel, Mrs. Annika Koller and Mrs. Mandy Axt for administering the training sessions as well as Dr. Lisa Roesser, Dr. Christiane Bauer and Dr. Ralf Lichthardt for their help in the recruitment of participants.

\section{Funding}

No funding was involved in design, in the collection, analysis, and interpretation of data, in the writing of the manuscript and in the decision to submit the manuscript for publication.

\section{Author details}

'Department of Psychiatry, Sozialstiftung Bamberg, St-.Getreu-Straße 14-18, 96049 Bamberg, Germany. ²Department of Physiological Psychology, Otto-Friedrich University Bamberg, Markusplatz 3, 96045 Bamberg, Germany. ${ }^{3}$ Centre for Psychiatry, Justus Liebig University School of Medicine Gießen, Am Steg 22, 35392 Gießen, Germany.

Received: 13 September 2012 Accepted: 28 June 2013 Published: 9 July 2013

\section{References}

1. Heinrichs RW, Zakzanis KK: Neurocognitive deficits in schizophrenia: a quantitative review of the evidence. Neuropsychology 1998, 12:426-445.

2. Aleman A, Hijman R, De Haan EHF, Kahn RS: Memory impairment in schizophrenia: a meta-analysis. Am J Psychiatry 1999, 156:1358-1366.

3. Dickinson D, Ramsey ME, Gold JM: Overlooking the obvious: a metaanalytical comparison of digit symbol coding tasks and other cognitive measures in schizophrenia. Arch Gen Psychiatry 2007, 64:532-542.

4. Cannon M, Caspi A, Moffitt TE, et al: Evidence for earlychildhood, pandevelopmental impairment specific to schizophreniform disorder: results from a longitudinal birth cohort. Arch Gen Psychiatry 2002, 59:449-456.

5. Asarnow RF, Nuechterlein KH, Subotnik KL, Fogelson DL, Torquato RD, Payne DL, et al: Neurocognitive impairments in nonpsychotic parents of children with schizophrenia and attentiondeficit/hyperactivity disorder: 
The University of California, Los Angeles Family Study. Arch Gen Psychiatry 2002, 59:1053-1060.

6. Nuechterlein KH, Asarnow RF, Subotnik KL, Fogelson DL, Payne DL, Kendler KS, et al: The structure of schizotypy: Relationships between neurocognitive and personality disorder features in relatives of schizophrenic patients in the UCLA Family Study. Schizophr Res 2002, 54:121-130.

7. Bora $E$, Yücel M: Pantelis C Cognitive impairment in schizophrenia and affective psychoses: implications for DSM-V criteria and beyond. Schizophr Bull 2010, 36(1):36-42.

8. Keefe RSE, Fenton WS: How should DSM-V criteria for schizophrenia include cognitive impairment? Schizophr Bull 2007, 33:912-920.

9. Green MF: What are the functional consequences of neurocognitive deficits in schizophrenia? Am J Psychiatry 1996, 153:321-330.

10. Green MF, Kern RS, Braff DL, Mintz J: Neurocognitive deficits and functional outcome in schizophrenia: are we measuring the "right stuff"? Schizophr Bull 2000, 26:119-136.

11. Green MF, Kern RS, Heaton RK: Longitudinal studies of cognition and functional outcome in schizophrenia: implications for MATRICS. Schizophr Res 2004, 72:41-51.

12. Fett AK, Viechtbauer W, Dominguez MD, Penn DL, van Os J, Krabbendam L: The relationship between neurocognition and social cognition with functional outcomes in schizophrenia: a meta-analysis. Neurosci Biobehav Rev 2011, 35(3):573-588.

13. Nuechterlein KH, Subotnik KL, Green MF, Ventura J, Asarnow RF, Gitlin MJ, et al: Neurocognitive predictors of work outcome in recent-onset schizophrenia. Schizophr Bull 2011, 37(Suppl. 2):S33-S40.

14. Holthausen EAE, Wiersma D, Cahn W, Kahn RS, Dingemans PM, Schene AH, van den Bosch RJ: Predictive value of cognition for different domains of outcome in recent-onset schizophrenia. Psychiatry Res 2007, 149:71-80.

15. Moritz S, Krausz M, Gottwalz E, Lambert M, Perro C, Ganzer S, Naber D: Cognitive dysfunction at baseline predicts symptomatic 1-year outcome in first-episode schizophrenics. Psychopathology 2000, 33:48-51.

16. Gråwe RW, Levander S: Neuropsychological impairments in patients with schizophrenia: stability and prediction of outcome. Acta Psychiatr Scand suppl 2001, 408:60-64.

17. Wölwer W, Brinkmeyer J, Riesbeck M, Freimüller L, Klimke A, Wagner M, Möller HJ, Klingberg S, Gaebel W: German Study Group on First Episode Schizophrenia. Neuropsychological impairments predict the clinical course in schizophrenia. Eur Arch Psychiatry Clin Neurosci 2008, 258(Suppl 5):28-34.

18. Eberhard J, Levander S, Lindström E: Remission in schizophrenia: analysis in a naturalistic setting. Compr Psychiatry 2009, 50(3):200-208.

19. Robinson D, Woerner MG, Alvir JMJ, Bilder R, Goldman R, Geisler S, Koreen A, Sheitman B, Chakos M, Mayerhoff D, Lieberman JA: Predictors of relapse following response form a first episode of schizophrenia or schizoaffective disorder. Arch Gen Psychiatry 1999, 56:241-247.

20. Stirling J, White C, Lewis S, Hopkins R, Tantam D, Huddy A, Montague L: Neurocognitive function and outcome in first-episode schizophrenia: a 10year follow-up of an epidemiological cohort. Schizophr Res 2003, 65:75-86.

21. Buckley PF, Harvey PD, Bowie CR, Loebel A: The relationship between symptomatic remission and neuropsychological improvement in schizophrenia patients switched to treatment with ziprasidone. Schizophr Res 2007, 94:99-106.

22. Wykes T, Huddy V, Cellard C, McGurk S, Czobar P: A metaanalysis of cognitive remediation for schizophrenia: methodology and effect sizes. Am J Psychiatry 2011, 168:472-485.

23. McGurk SR, Twamley EW, Sitzer DI, McHugo GJ, Mueser KT: A meta-analysis of cognitive remediation in schizophrenia. Am J Psychiatry 2007, 164:1791-1802.

24. Grynszpan O, Perbal S, Pelissolo A, Fossati P, Jouvent R, Dubal S, Perez-Diaz F: Efficacy and specificity of computer-assisted cognitive remediation in schizophrenia: a meta-analytical study. Psychol Med 2011, 41(1):163-173.

25. Wykes T, Spaulding WD: Thinking about the future cognitive remediation therapy-what works and could we do better? Schizophr Bull 2011, 37(Suppl 2):S80-S90.

26. Trapp W, Hasmann A, Gallhofer B, Schwerdtner J, Guenther W, Dobmeier M: Cognitive Improvement of Schizophrenia Patients: Enhancing Cognition while Enjoying Computer-Aided Cognitive Training. Clin Sch Rel Psych 2008, 1(4):307-316

27. Trapp W: X-Cog user manual. Erlangen: Gruner; 2003.

28. First MB, Williams JB, Spitzer RL: Structured Clinical Interview for DSM-IV Axis I Disorders (SCID-I). Washington, D.C.: American Psychiatric Press, Inc; 1997.
29. Andreasen NC: The Scale for the Assessment of Postivie Symptoms (SAPS) Iowa City. IA: The University of lowa; 1984.

30. Andreasen NC: The Scale for the Assessment of Negative Symptoms (SANS) lowa City. IA: The University of lowa; 1984.

31. Zerssen D: Paranoid-Depressivitäts-Skala sowie Depressivitäts-Skala-Manual. Weinheim: Beltz; 1976. German.

32. Young DA, Freyslinger MG: Scaffolded instruction and the remediation of Wisconsin Card Sorting Test deficits in chronic schizophrenia. Schizophr Res 1995, 16(3):199-207.

33. Wechsler D: Wechsler Memory Scale_Revised manual. San Antonio: The Psychological Corporation; 1987.

34. Reitan RM: Validity of the trail making test as an indicator of organic brain damage. Percept Mot Skills 1958, 8:271-276.

35. Nuechterlein $\mathrm{KH}$, Parasuraman R, Jiang Q: Visual sustained attention: image degradation produces rapid sensitivity decrement over time. Science 1983, 220:327-329.

36. Nuechterlein KH, Edell WS, Norris M, Dawson ME: Attentional vulnerability indicators, thought disorder, and negative symptoms. Schizophr Bull 1986, 12:408-426.

37. Rosner B: Fundamentals of Biostatistics. 7th edition. Boston, MA: Brooks/Cole; 2011.

38. Lang U: Kognitive Defizite bei Schizophrenien. Evaluation des computergestützten kognitiven Trainings X-Cog. Regensburg: Roderer; 2006. German.

39. Bowie CR, Leung WW, Reichenberg A, McClure MM, Patterson TL, Heaton RK, Harvey PD: Predicting schizophrenia patients' real world behavior with specific neuropsychological and functional capacity measures. Biol Psychiatry 2008, 63:505-511.

40. Milev P, Ho BC, Arndt S, Andreasen NC: Predictive values of neurocognition and negative symptoms on functional outcome in schizophrenia: a longitudinal first-episode study with 7-year follow-up. Am J Psychiatry 2005, 162:495-506.

41. Wittorf A, Wiedemann G, Buchkremer G, Klingberg S: Prediction of community outcome in schizophrenia 1 year after discharge from inpatient treatment. Eur Arch Psychiatry Clin Neurosci 2008, 258:48-58.

42. Brewer WJ, Francey SM, Wood SJ, Jackson HJ, Pantelis C, Phillips $\sqcup$, Yung AR, Anderson VA, McGorry PD: Memory impairments identified in people at ultra-high risk for psychosis who later develop first-episode psychosis. Am J Psychiatry 2005, 162:71-78.

43. Lencz T, Smith CW, McLaughlin D, Auther A, Nakayama E, Hovey L, Cornblatt BA: Generalized and specific neurocognitive deficits in prodromal schizophrenia. Biol Psychiatry 2005, 59:863-871.

44. Whyte MC, Brett C, Harrison LK, Byrne M, Miller P, Lawrie SM, Johnstone EC: Neuropsychological performance over time in people at high risk of developing schizophrenia and controls. Biol Psychiatry 2006, 59:730-739.

45. Fowles D: Schizophrenia: diathesis-stress revisited. Annu Rev Psychol 1992, 43:303-336.

46. Nuechterlein $\mathrm{KH}$, Dawson ME, Ventura J, et al: The vulnerability/ stress model of schizophrenic relapse: a longitudinal study. Acta Psychiatr Scand Supp/ 1994, 382:58-64.

47. Walker E, Diforio D: Schizophrenia: a neural diathesis-stress model. Psychol Rev 1997, 104:667-685.

48. Lieberman JA, Stroup TS, McEvoy JP, Swartz MS, Rosenheck RA, Perkins DO, Keefe RS, Davis SM, Davis CE, Lebowitz BD, Severe J, Hsiao JK: Clinical Antipsychotic Trials of Intervention Effectiveness (CATIE) Investigators. Effectiveness of antipsychotic drugs in patients with chronic schizophrenia. NEngl J Med 2005, 13(12):1209-1223.

49. EUFEST study group, Kahn RS, Fleischhacker WW, Boter H, Davidson M, Vergouwe Y, Keet IP, Gheorghe MD, Rybakowski JK, Galderisi S, Libiger J, Hummer M, Dollfus S, López-lbor JJ, Hranov LG, Gaebel W, Peuskens J, Lindefors N, Riecher-Rössler A, Grobbee DE: Effectiveness of antipsychotic drugs in first-episode schizophrenia and schizophreniform disorder: an open randomised clinical trial. Lancet 2008, 13(9618):1085-1097.

50. Alonso J, Croudace T, Brown J, Gasquet I, Knapp MR, Suárez D, Novick D: Health-related quality of life (HRQL) and continuous antipsychotic treatment: 3-year results from the Schizophrenia Health Outcomes (SOHO) study. Value Health 2009, 12(4):536-543.

\section{doi:10.1186/1471-244X-13-184}

Cite this article as: Trapp et al:: Cognitive remediation improves cognition and good cognitive performance increases time to relapse results of a 5 year catamnestic study in schizophrenia patients. BMC Psychiatry 2013 13:184. 